Research article

JMCJMS

\title{
Medicine counseling services at Tertiary care Hospital in Nepal
}

\author{
Bajracharya 0, Shankar PR, Jha N, Banstola A, Shrestha R, Thapa H \\ Department of Clinical Pharmacology and Therapeutics, KIST Medical College, Lalitpur, Nepal
}

\begin{abstract}
Background and Objectives: Patient needs specific guidelines from their pharmacist in support of better compliance of their medicine used. Counseling of the patient and patient representative is important for improving the therapeutic out comes. Counseling patients can improve their understanding regarding medication, disease and life style modifications which in turn improves compliance.
\end{abstract}

Material and Methods: Patients and/or patient party were counseled as per the Omnibus Budget Reconciliation Act-1990 guidelines. The data was collected as per OBRA-90 during the period of eighteen month and was analyzed using statistical software SPSS version 17.

Results: Three hundred and fifty patients were counseled during the study period. Majority of the counseled patients were females [75.9\%]. Mean counseling time taken by the pharmacist was 7.43 minute. Minimum time taken to counsel the patient was $6-10$ minutes in $58.41 \%$ of the counseled, followed by less than 5 minutes in $19.68 \%$ and $11-15$ minutes in $8.89 \%$. About $10.47 \%$ were counseled for more than 15 minutes by the pharmacist. Greater numbers of the patients referred to the Medicine Counseling Center (MCC) were from Obstetrics and Gynecology departments and most of them were directed by doctors [50.47\%].

Conclusion: This study highlights that role of doctor is important to encourage patient to attend counseling services. Counseling is the integral part that not only help patient to understand the use of their medicine but also to improve their therapeutic out comes. The effect of counseling on compliance should be studied in future.

Keywords: Medicine counseling, Omnibus Budget Reconciliation Act-1990, MCC, Nepal

\section{INTRODUCTION}

Non compliance is one of the important factors that lead to failure of the drug therapy. Various documents regarding problem of non compliance have been documented even in the developed countries [1]. There are several reasons for non compliance among them, the 
most common being adverse drug reaction (ADRs) due to medications, poor understanding of instructions and frequent intake of medicines among others [2, 3].

For any disease to be treated it is equally important that not only doctors but the patient should also know regarding the disease condition he/she is suffering from and management of the same. If these things are considered during the treatment then lot of things we can minimized in regards to non compliance. Apart from that a number of strategies have been taken to improve patient compliance. One of the methods is counseling. Medication counseling is defined as "providing medication related information orally or in written form to the patients or their representatives, on topics like directions for use, advice on side effects, precautions, storage, diet and life style modification"[4].

Looking at present scenario of Nepal due to poor literacy rate and low economic status, patients cannot obtain adequate information regarding the disease and its treatment. Beside this around $70 \%$ of doctors are stationed in the urban area compare to that of ruler. It has estimated that the doctor -patient ratio in Kathmandu is 1:800, while the ratio in the hills and remote areas is 1:3000 [5]. This Indicate, the number of patient visiting physician will be more which ultimately effect total time spent with patient, i.e. doctor has less time for their patient. If the doctor has a less time with patient, they will not be able to give complete information regarding the safer and appropriate use of the medicine for the treatment of the disease. Also patient information leaflets and package inserts are not mandatory by law in the country. Even the dispensing pharmacist do not provide adequate information to the patients which may lead to noncompliance and ultimately to reduction in therapeutic outcomes. In these conditions medicine counseling plays an important role.

Medication counseling is usually done by the pharmacist. Several studies agree that counseling by the pharmacist can improve patient's understanding about medication and lifestyle modifications $[6,7]$. The goal of counseling is to provide information to encourage safe and appropriate use of medications, in order to improve therapeutic outcomes ${ }^{7}$. Similar type of study was conducted in South India in diabetic patient concluded that counseling done by the pharmacist not only improve better control in diabetes but also improve their quality of living which eventually means improve in therapeutic outcomes [8].

Medicine counseling is a new concept in Nepal. Manipal Teaching Hospital, Pokhara was the first to establish a medication counseling centre (MCC). The centre has played a vital role in improving compliance with and outcomes of treatment. KIST Medical College (KISTMC) was the second institution to establish a MCC [9]. The MCC was started on $17^{\text {th }}$ June 2008 in the hospital outpatient department (OPD). The main aim of establishment of MCC was to improve patient understanding and compliance with treatment to improve therapeutic outcomes [10]. The centre has emphasized counseling of medicines which use modified drug delivery system for example: Metered Dose Inhaler (MDI), Dry Powder Inhaler (DPI), pessaries etc. Various counseling aids are used and patients are counseled regarding medications and its use, disease, lifestyle modifications and use of medication devices. Counseling in MCC is done as per the Omnibus Budget Reconciliation Act -1990 (OBRA-90) [11]. 
The objectives of the present study were to

1. Study the demographic details of patients visiting the medication counselling centre

2. Study the purpose of their visit to MCC

3. Note various aids used by pharmacists during counselling process, and

4. Note the content of counseling provided to the patients

\section{MATERIAL AND METHODS}

For this study, the completed counseling forms during the period from $17^{\text {th }}$ June 2008 to $31^{\text {st }}$ December 2009 were considered. Most patients who visited the MCC were either referred by the physician or the dispensing pharmacist. The MCC was established in a separate room located in the outpatient department of the hospital. Then the patient was made to sit comfortably and counseled regarding the use of medicines and medicine delivery system to obtain better therapeutic outcomes.

The counseling documentation form includes: hospital number, patient's demographic details, date at which counseled, and department from which they have been referred. Details regarding purpose of their visit were also noted. Pre-evaluation was done to note patient's level of knowledge regarding the use of the medicine. This was only done with the patients who were already using or had been using the medication and/or devices for administration of medicine. Measuring the level of their knowledge they were then counseled once again in order to improve their understanding regarding the medicine use.

Various counselling aids were used in order to improve understanding regarding the medicine use. If patients were unable to understand the counseling provided then counseling was also provided to the patient's representatives. This was mainly done in elderly, children and in patients who required repeated counseling.

Counseling was done as per OBERA-90 recommendations and time spent and explanation given by the counseling pharmacist were also noted and documented for future reference. The data obtained was entered in SPSS version 17 and analyzed as per the study objectives.

\section{RESULTS}

During the eighteen month period 315 patients were counseled in the MCC. Among these majority were females [75.9\% $(n=239)]$.

\section{Table 1: demographic characteristic of the patients}

\begin{tabular}{|c|c|c|}
\hline Characters & $\begin{array}{c}\text { No. of } \\
\text { patients }\end{array}$ & $\begin{array}{c}\text { Percentage } \\
\text { (\%) }\end{array}$ \\
\hline Gender & 76 & 24.1 \\
Male & 239 & 75.9 \\
\hline Female & & \\
Age group & 11 & 3.4 \\
$<=10$ & 8 & 2.5 \\
$11-20$ & 64 & 20.3 \\
$21-30$ & 69 & 21.9 \\
$31-40$ & 55 & 17.4 \\
$41-50$ & 40 & 12.6 \\
$51-60$ & 43 & 13.6 \\
$61-70$ & 24 & 7.6 \\
$>70$ & 2 & 0.6 \\
\hline Not mentioned & & \\
\hline
\end{tabular}


Table 1 shows the demographic details of the patients who received counseling. Maximum numbers of the patients counseled were between age of 31-40 years (21.9\%), followed by $21-30$ years $(20.3 \%)$ and $41-50$ years (17.4\%).

Table 2: Counseling aids used to counsel the patients

\begin{tabular}{|l|c|c|}
\hline \multicolumn{1}{|c|}{ Counseling aids } & $\begin{array}{c}\text { Total no. of } \\
\text { counseling } \\
\text { aids }\end{array}$ & $\begin{array}{c}\text { Percentage } \\
\text { (\%) }\end{array}$ \\
\hline $\begin{array}{l}\text { Metered dose } \\
\text { inhaler }\end{array}$ & 55 & 17.4 \\
\hline $\begin{array}{l}\text { Rota haler (Dry } \\
\text { powder inhaler) }\end{array}$ & 45 & 14.28 \\
\hline Pessaries & 182 & 57.77 \\
\hline Insulin pen & 20 & 6.34 \\
\hline Spacer, baby mask & 3 & 0.9 \\
\hline Eye/ear drops & 10 & 3.17 \\
\hline
\end{tabular}

The most common department from where patients were referred to the MCC was Obstetrics and Gynaecology. Most patients who visited MCC were referred by doctors [50.47\% $(n=159)]$ followed by pharmacists $[42.22 \%$ $(n=133)]$ and other healthcare providers $[3.80 \%$ $(n=12)]$. However, $3.49 \%(n=11)$ of the patients visited the MCC based on their own interest.

For counseling purpose pharmacists used certain counseling aids. Table 2 shows the details regarding the use of counseling aids. Six patients $(1.9 \%)$ who were already using MDI or DPI refused counseling stating that they had already used the devices and knew how to use it. Among the total patients involved in the study, $61 \%$ of the counseling was exclusively given to the patient only, followed by $20 \%$ for both the patient and their relatives and $18 \%$ were done to the patients' relatives only.

Various points covered during counseling as per OBRA-90 recommendations were also studied.
Table 3 shows the details of the same. Minimum time take to counsel the patient was 6-10 minutes in $58.41 \%$ of patients $(n=184)$ followed by less than 5 minute in $19.68 \%(n=62)$, and 11 15 minutes in $8.89 \%(n=28)$. Patients who had been counseled more than 15 minutes were $10.47 \%(n=33)$ and in remaining $2.54 \%(n=8)$ time spent by the pharmacist on counseling was not mentioned. Mean counseling time taken by the pharmacist was 7.43 minute.

Table 3: Points covered during counseling as per the OBRA-90 recommendations

\begin{tabular}{|l|c|c|}
\hline \multicolumn{1}{|c|}{ Point covered } & $\begin{array}{c}\text { Total no. } \\
\text { of patients }\end{array}$ & $\begin{array}{c}\text { Percentage } \\
\text { (\%) }\end{array}$ \\
\hline $\begin{array}{l}\text { Description of the } \\
\text { medicine }\end{array}$ & 315 & 100 \\
\hline Dose & 304 & 96.50 \\
\hline Dosage form & 315 & 100 \\
\hline Route & 315 & 100 \\
\hline Duration & 311 & 98.73 \\
\hline $\begin{array}{l}\text { Special directions for } \\
\text { administration }\end{array}$ & 294 & 93.33 \\
\hline $\begin{array}{l}\text { Precautions to be taken } \\
\text { during administration }\end{array}$ & 56 & 17.99 \\
\hline Common side effects & 228 & 72.38 \\
\hline $\begin{array}{l}\text { Self monitoring } \\
\text { technique }\end{array}$ & 210 & 66.66 \\
\hline Proper Storage & 248 & 78.73 \\
\hline Refill information & 230 & 73.01 \\
\hline Missed dose & 98 & 31.5 \\
\hline Follow up & 289 & 91.74 \\
\hline
\end{tabular}

Most of the patients who were counseled gave positive feedback on the counseling services provided by the MCC centre at KIST Medical College. However some patients were in a view that this kind of services should not only be concentrated on a few special medications but should be given to all other medicines which patients are using.

\section{DISCUSSION}

The study evaluated the functioning of medicine counseling centre in KISTMC from $17^{\text {th }}$ June 2008 to 31st December 2009. 
The main purpose of establishing MCC was to provide medicine related information to patients or their relatives with an objective of encouraging safe and effective use of medicine and improving therapeutic outcomes. In the period of eighteen months, the MCC had counseled 315 patients, limited to the counseling of medicines which have special drug delivery systems like Metered Dose Inhaler (MDI), Dry Powder Inhaler (DPI), Pesarries etc.

Counseling of patients was done as per OBRA-90 recommendations which emphasized the delivery of certain information on the use of medicine provided to them. Recently in Nepal, good pharmacy practice (GPP) guidelines have been drafted, which also includes certain guidelines for the pharmacist to counsel the patients [12].

Among the counseled patient most of the patients who had been counseled were from Obstetrics and Gynecology department. For the treatment of various infections antimicrobial drugs in the dosage form of vaginal pessaries were used, which is among the most preferred dosage form for the above mentioned condition. For the proper administration and better therapeutic outcomes these medicine need stepwise counseling without which failure of therapy might occur. Therefore these patients were counseled and this could be one of the important reasons why this department had send maximum number of patients and beside this gynecologist were closely associated with medicine counseling service. Apart from the administration of the drug, non-pharmacological measures like maintenance of proper hygiene during and after the treatment were also mentioned, which are usually a part of medication counseling. The second highest number of patients was counseled regarding the use of inhalation devices which require proper counseling, without which therapeutic outcome will not be achieved. A study states counseling patients using MDI is very essential. It has been shown that approximately $75 \%$ of the patients using MDIs do not use them properly [13]. Proper counseling regarding use of such devices will improve compliance of patients and ultimately result in improvement in therapeutic outcomes [14].

Maximum number of the patients counseled lies between age of 21-50 years. This is mainly because of majority of the patients were from Obstetrics and Gynecology department.

For better understanding, the pharmacists used 'counseling aids' as proper counseling tools in order to improve the use of their medication. Table 2 shows various counseling aid used like bronchial model to make them compare between the disease and non disease conditions, inhalation devices like dry power inhaler, insulin pen. A similar study done in Manipal Teaching Hospital had found that use of counseling aids will improve patient concordance and therapeutic outcomes [15].

Time factor is important while counseling patients. In our study, the pharmacists spent 610 minutes on counseling for more than half of the patients. The mean average time spend by the pharmacist to counsel the patient and/or their relatives were around 7.43 minutes. The study done in Manipal Teaching Hospital showed maximum time spent with the patient while counseling was 6-10 minute. Spending enough time with the patient is an important factor in counseling and more time spent will certainly have a positive impact on counseling $[16,17]$.

Satisfaction with the treatment is achieved only when the disease condition is improved. Medicine counseling is one of the important medium to improve such disease condition. 
This is because; if the counseling of the medicines is done properly the patients who are taking medicine will use it correctly. Therefore during our study period $3.1 \%$ of the patients were in the opinion that the counseling should not be limited for special preparations or specific medicines but should be made for all medications.

Most of the patient who visited the MCC services was referred by the doctors. Since doctors are the respectable person and almost all of the patient belief the advice given to them by their doctors. The study have shown that if the patient belief their physician who show concern towards their patient then this will help in improving the health of their patient by increasing compliance [18]. Therefore if they refer their patients to visit medicine counseling centre then without failing they come to the centre. This shows that role of doctor plays an important to encourage patient to visit MCC. This encouragement will ultimately improve therapeutic outcomes.

\section{CONCLUSION}

The time spent by the pharmacists was adequate and in some cases, along with patient their relatives were also counseled for better therapeutic outcomes. This should not only be limited to the certain drug delivery system but should be use to counsel the entire pharmaceutical products as possible. Apart from that role of doctor is important to encourage patient to attend counseling services which eventually improve patient knowledge regarding the safer and appropriate use of medication more rationally. Therefore it can be concluded that MCC at KIST Medical College played an important role in informing patients regarding safe and effective use of their medications which ultimately leads to rational use of medicine.

Limitation of the study: As this was a retrospective study patient satisfaction with the counseling process was not measured.

\section{ACKNOWLEDGEMENT}

The authors would like to acknowledge all the doctors of KIST Medical College for their support. They acknowledge the help of the college management in establishing Medicine Counseling Center.

\section{REFERENCES}

1. McKenney JM, Harrison WL. Drug-related hospital admissions. Am J Hosp Pharm 1976; 33: 792-95

2. Anupa KC, Durga B, Subish P, Mishra P. Patient counseling by pharmacists- a novel approach to enhance patient compliance. J Nep Pharm Assoc. $2005 ; 23: 17-22$.

3. Buabeng $\mathrm{OK}$, Matowe L, Plange-Rhule J. Unaffordable drug prices: the major cause of noncompliance with hypertension medication in Ghana. J Pharm Pharmaceut Sci. 2004; 7(3):350-2.

4. USP Medication counseling behaviour guideline. USPDI update volumes I and II Rockville, the United States Pharmacopeia Convention Inc, 1997, 664-75,1739-48.

5. Maharjan L. The Himalayan Times Daily Nepal, 2010. (Cited 25 February 2013). Available from: http://www.thehimalayantimes.com/fullNews.ph $\mathrm{p}$ ?headline $=$ Number + of + doctors + to + double $+\mathrm{in}+\mathrm{h}$ ospitals\&NewsID $=244059$

6. Jaber LA, Halapy H, Fernet M, Tummalapalli S, Dewakran H. Evalaution of pharmaceutical care model on diabetes management. Ann Pharmacother. 1996; 30: 238-2.

7. Palaian S, Acharya LD, Rao PGM, Shankar PR, Nair NM, Nair NP. Evaluation of the impact of patient counseling in terms of knowledge, attitude and 
practice outcomes of hospitalized diabetic patients. P and T Journal 2006; 31 (7): 383-400.

8. Dooley M, Lyall H, Galbriath et al. SHPA standards of practice for clinical pharmacy. In: SHPA practice standards and definitions 1996. p. 2-11

9. Rasheed A, Ramesh A, Nagavi BG. Improvement in quality of life through patient counseling. Pharmatimes 2002: 34; 9-10, 14.

10. Shankar PR, Shrestha RK, Banstola A, Thapa HS, Piryani RM Initiating and Strengthening Nepal's Second Medication Counseling Center - Our Experiences The Pharma Review.(Cited 27 February 2013) Available from: http://www.kppub.com/articles/jan2010/initiati ng.html

11. Mishra P, Subish P, Upadhyay DK, et al. Medication counseling center in a teaching hospital. JNMA J Nepal Med Assoc. 2005; 44 (160):129-34

12. Omnibus Budget Reconciliation. Act of 1990, Pub. L .no. 101-508, and 4401, 104 stat 1388, 1990.

13. Gibbs KP, Small M. Asthma In: Walker R, Edwards C 'editors'. Clinical Pharmacy and Therapeutics. 3rd edition. Philadelphia: Churchill Livingstone 2003; 375- 95 .
14. National Good Pharmacy Practice Guidelines (Draft). Developed by Nepal Pharmacy Council, Kathmandu, Nepal, November 2005

15. Alam K, Palaian S, Mishra P, Sah AK, Upadhyay DK, Bhandari RB. Performance of the medication counseling center in Manipal Teaching Hospital: A follow up study. Journal of Clinical and Diagnostic Research. 2009; 3:1319-1325.

16. Ramesh A (1999). Patient Counseling. In Proceedings:National seminar on advances in industrial pharmacy and pharmacy practice 1999, 17th-18th Oct. JSS College of pharmacy, Mysore, India

17. Sczupak CA, Conrad WF. Relationship between patient-oriented pharmaceutical services and therapeutic outcomes of ambulatory patients with diabetes mellitus. Am J Hosp Pharm 1977; 34:1238-42.

18. Falvo D, Woehlche P Dichmann J. Relationship of doctor behavior to patient compliance. Patient Couns Health Educ. 1980; 2:185-88. 